\title{
INVESTIGATIONS OF THE DYNAMICS AND GROWTH OF SURFACES AND ULTRA THIN FILMS BY HELIUM ATOM SCATTERING
}

\author{
Final Report \\ for the Project Period from \\ November 1, 2000 to October 31, 2003 \\ from \\ S. A. Safron, Professor of Chemistry, CO-PI \\ J. G. Skofronick, Professor of Physics, PI \\ D. H. Van Winkle, Professor of Physics, CO-PI \\ Helium Atom Surface Scattering Group \\ Physics and Chemistry Departments \\ and \\ Center for Materials Research and Technology \\ The Florida State University \\ Tallahassee, Florida 32306-4350 \\ February 13, 2006 \\ Prepared for \\ U. S. DEPARTMENT OF ENERGY \\ GRANT NO. DE-FG02-97ER45635 \\ ESTIMATE of UNEXPENDED FUNDS: \$0
}

This report was prepared as an account of work sponsored by the United States

Government. Neither the United States Department of Energy, nor any of their employees, nor any of their contractors, subcontractors, or their employees, makes any warranty, express or implied, or assumes any legal liability or responsibility for the accuracy, completeness or usefulness of any information, apparatus, product or process disclosed or represents that its use would not infringe privately-owned rights. 


\section{Progress Report: November 1, 2000 - October 31, 2001}

\section{Aims}

The aim of this work is to study the structure and dynamics of crystalline surfaces. The materials under investigation at this time are metal oxides and organic insulators grown as ultra thin films onto crystalline substrates. We have focused on insulating surfaces and films because they have special materials properties which are of current interest and, in particular, their structures and lattice dynamics remain largely unexplored since they are difficult to examine with other surface science techniques. Helium Atom Scattering (HAS) is unique among these techniques in employing a low-energy, electrically neutral and non-penetrating probe that does not charge or damage the surface.

While there are many technologically important oxide surfaces which could be studied, we have so far restricted our efforts to the perovskite $\mathrm{KTaO}_{3}$, pure and doped with $\mathrm{Nb}$, and $\mathrm{TiO}_{2}$. At the same time we have continued our characterization of ultra thin polyphenylene films vapordeposited onto alkali halide (001) substrates. We described the results of experiments on pure $\mathrm{KTaO}_{3}$ in our Progress Report for last year. During this project period we have concentrated on the cleaved (001) surfaces of the mixed perovskites $\mathrm{KTa}_{1-\mathrm{x}} \mathrm{Nb}_{\mathrm{x}} \mathrm{O}_{3}$, where $\mathrm{x}$ is the mole fraction of $\mathrm{Nb}$, which so far has ranged from about 6 to $52 \mathrm{~mol} \%$, and have started experiments on the $\mathrm{TiO}_{2}(110)$ surface. We would like to complete the range of niobium-doped $\mathrm{KTaO}_{3}$ by carrying out experiments on the (001) surface of $\mathrm{KNbO}_{3}(\mathrm{x}=1)$.

We reported in our work on pure $\mathrm{KTaO}_{3}$ the observation of several Einstein-like modes which our German theoretical collaborators have attributed to vibrations of essentially isolated $\mathrm{K}^{+}$at the surface. Doping by $\mathrm{Nb}$ does not appear to change the energetics of these modes, which is consistent with this model. However, we plan to test this further by substituting other alkali metals such as $\mathrm{Na}$ or $\mathrm{Rb}$ for $\mathrm{K}$, which should substantially alter the Einstein-mode energies.

Although not part of our original plans, we expect to take advantage of the sabbatical visit of Prof. Gung Chern (National Chung- Chen University, Taiwan) to the National High Magnetic Field Laboratory this Summer and Fall, 2001, to collaborate on a project to characterize a film of $\mathrm{Mg}$ grown onto $\mathrm{MgO}(001)$. This will provide an opportunity to research an insulator-to metal transition with HAS.

We note finally that we are still interested in (i) physisorbed films of molecular hydrogen and its isotopes on graphite at very low temperatures; (ii) the surface behavior of $\mathrm{NH}_{4} \mathrm{Cl}$ produced by the reaction of $\mathrm{HCl}$ and $\mathrm{NH}_{3}$; and (iii) the growth dynamics and structure of $\mathrm{KCl}$ on 
$\mathrm{NaCl}(001)$.

The aims of the grant have not changed in any significant way.

\section{Work Accomplished to Date}

Most of the HAS beam time has been used to study the surfaces of $\mathrm{KTa}_{1-\mathrm{x}} \mathrm{Nb}_{\mathrm{x}} \mathrm{O}_{3}$, with $\mathrm{x}=6$, 10, 20, 30 and $52 \mathrm{~mol} \%$. This work is an extension of the experiments on the pure $\mathrm{KTaO}_{3}$ by our former student, Jaime Li, which is being carried out in collaboration with L. A. Boatner (Oak Ridge National Laboratory). Previous work had revealed three structural phase changes in the bulk (cubic to tetragonal to orthorhombic to rhombohedral) as the temperature is reduced for these doped materials, but our measurements have yielded evidence for very unusual structural features that are localized to the surface. The results of these helium diffraction and inelastic scattering experiments will form the $\mathrm{Ph}$. D. dissertation of Tom Trelenberg who is now analyzing the data and interpreting his experiments. In our next year's Progress Report, we will be able to give a complete overview of this extensive study. The first paper to come from this massive effort has now been accepted by Physical Review Letters. It reports on the metastable features observed for freshly cleaved $\mathrm{KTaO}_{3}(001)$ which are described in Jaime Li's dissertation.

The HAS instrument is currently being used to study $\mathrm{TiO}_{2}$ (110) (rutile), a metal oxide of considerable technological interest in gas sensing, catalysis and photocatalysis, but one that has not been studied by helium scattering. Previous work on this surface has been carried out primarily by STM investigations and is comparable to some extent with our studies. These efforts have also been very useful in guidance for the preparation of this surface which cannot be obtained by cleaving. The preparation starts with a cut and polished (110) surface of $\mathrm{TiO}_{2}$ and involves sputtering and annealing to $700^{\circ} \mathrm{C}$. This would be a most unusual procedure for any of our previous studies on insulator metal oxide surfaces. We are now six weeks into experiments on this new surface and are very pleased with the results. The He angular distributions continue to increase in intensity and quality with repeated treatments, and we expect to find the optimum conditions for the ion bombardment and annealing soon. The measurements on $\mathrm{TiO}_{2}$ are being done by Shan Akhadov and will form the basis of his Ph.D. dissertation.

The third leg of our research effort this year has been on films of p-quaterphenyl vapordeposited onto $\mathrm{NaCl}(001)$ surfaces, using HAS, AFM and Grazing Incidence X-Ray Diffraction (GIXRD) carried out at the synchrotron facility at Grenoble, France, in collaboration with Dr. Detlev Smilgies. The different techniques have revealed a surprising amount of structure even for rather thick films ( $>20$ layers). In the HAS experiments at surface temperatures of 40-50 K, helium diffraction shows a number of diffraction spots which appear at all azimuths, as in a 
powder pattern. This suggests that these compounds form small, randomly ordered crystallites on the surface. However, much more work on different molecules and substrates has to be carried out before the systematics can be worked out. Both HAS and AFM studies are planned for this laboratory, and the GIXRD work will be carried out with Dr. Smilgies now at Cornell University. We are also considering joining efforts with Prof. Dr. H.-G. Rubahn (Fysisk Institut, Odense Universitet, Denmark) who is also interested in these materials. The experiments on the polyphenylene films will form the Ph. D. dissertation of Ed Kintzel, Jr. A first paper on this work has been accepted for publication in the Journal of Vacuum Science and Technology.

The collaboration (of JGS) with the Toennies Group at the Max Planck Institute in Göttingen, Germany, is still underway with a first paper submitted to Physical Review B on the surface structure and dynamics of an in situ- cleaved $\mathrm{MgO}(001)$ surface. There are two additional papers in preparation reporting on HAS experiments with this surface. One concerns a study with adsorbed molecular hydrogen and its isotopes and the second deals with the behavior of adsorbed $\mathrm{N}_{2}$.

We proposed last year to carry out HAS experiments on $\mathrm{H}_{2}$ films adsorbed at very low temperatures on graphite surfaces. Such work could test fundamental theory because they are relatively simple systems and because there is currently an in-house theorist at FSU who is very interested in these systems and has already made predictions regarding the behaviors which we think we can measure. To prepare for these measurements, we are continuing to construct and test a new cryostat/manipulator for the HAS instrument. This modification will permit measurements to approximately $3 \mathrm{~K}$ and, hopefully, as low as about $0.5 \mathrm{~K}$ when a ${ }^{3} \mathrm{He}$ refrigerator stage is added. This will make possible studies of quantum films, e.g., of $\mathrm{H}_{2}$ and its isotopes on graphite and other substrates.

\section{Estimate of Unexpended Funds}

We expect to have spent or obligated all of the funds from this grant by the end of the current budget period, October 31, 2001.

\section{Scientific Staff}

The current scientific personnel consist of the principal investigator, J. G. Skofronick (Physics Department) and co-principal investigators S. A. Safron (Chemistry Department) and D. H. Van Winkle (Physics Department). There are three senior graduate students in the group, T. W. Trelenberg, E. A. Akhadov and E. J. Kintzel, Jr. The first two of these students will likely finish later this year and the third early next year. One new graduate student has joined our 
group this year. Also working with us is Prof. Frank Flaherty of the Physics Department, Valdosta State University, in Valdosta, Georgia. He is able to visit FSU one day per week during the academic year and has been collaborating on the organic film work and on the $\mathrm{Nb}$ doped $\mathrm{KTaO}_{3}$ experiments. A senior undergraduate physics student, J. D. Brock, joined the group last summer for the research experience and has worked with us part-time for the entire year. This Spring semester two Honors General Chemistry students, Shara Wang and Erin Godwin, participated in experiments our lab, primarily, in studies with the AFM instrument.

V. Publications: Published, Accepted and Submitted, November 1, 2000-October 31, 2001

1. "Observation of a Metastable Periodic Structure for the (001) Surface of $\mathrm{KTaO}_{3}$ after Cleaving in situ", Jaime A. Li, E. A. Akhadov, Jeff Baker, L. A. Boatner, F. A. Flaherty, J. Fritsch, S. A. Safron, U. Schroeder, J. G. Skofronick, T. W. Trelenberg and D. H. Van Winkle, Phys. Rev. Lett. (in press).

2. "Investigation of the Morphology of the Initial Growth of Aromatic Molecule pQuaterphenyl on $\mathrm{NaCl}(001)$ ), E. J. Kintzel, Jr., D. M. Smilgies, J. G. Skofronick, S. A. Safron, D. H. Van Winkle, T. W. Trelenberg, E. A. Akhadov and F. Flaherty, J. Vac. Sci. Tech. (in press).

3. "Helium Atom Scattering Study of the Surface Structure and Dynamics of in situ Cleaved MgO(001) Single Crystals", G. Benedek, G. Brusdeylins, D. Schmicker, S. Schmidt, V. Senz, J. G. Skofronick, J. P. Toennies, F. Traeger and R. Vollmer, (Submitted to Phys. Rev. B).

\section{Abstracts and Papers Presented at Meetings: November 1, 2000-October 31, 2001.}

1. "Helium Atom Scattering Study of the Surface Structure and Dynamics of in situ Cleaved MgO(001) Single Crystals", J. G. Skofronick, G. Benedek, G. Brusdeylins, D. Schmicker, S. Schmidt, V. Senz, J. P. Toennies, F. Traeger and R. Vollmer, given at the 47th International Symposium of the American Vacuum Society, October 2-6, 2000, Boston, MA, p. 201.

2. "Analysis of the Surface Morphology of the Initial Growth Layers of p-Quaterphenyl on $\mathrm{NaCl}$ (001)”, E. J. Kintzel, Jr., E. A. Akhadov, T. W. Trelenberg, D. H. Van Winkle, J. G. Skofronick, S. A. Safron, F. Flaherty and D. -M. Smilgies, given at the 47th International Symposium of the American Vacuum Society, October 2-6, 2000, Boston, MA, p. 138.

3. "Investigation of Surface Structure and Dynamics of $\mathrm{H}_{2}, \mathrm{p}-\mathrm{H}_{2}, \mathrm{HD}$ and $\mathrm{D}_{2}$ Molecules Adsorbed on in situ Cleaved $\mathrm{MgO}(001)$ by Helium Atom Scattering", J. G. Skofronick, J. P. 
Toennies, F. Traeger and H. Weiss, Bull. Am. Phys. Soc. 46, 189 (2001).

4. "Observation of a Metastable Periodic Structure for the (001) Surface of $\mathrm{KTaO}_{3}$ after Cleaving in situ", T. W. Trelenberg, E. A. Akhadov, J. A. Li, J. G. Skofronick, S. A. Safron, D. H. Van Winkle, L. A. Boatner and F. A. Flaherty, Bull. Am. Phys. Soc. 46, 306 (2001).

5. "Observation of a Metastable Periodic Structure for the (001) Surface of $\mathrm{KTaO}_{3}$ after Cleaving in situ", J. D. Brock, E. A. Akhadov, L. A. Boatner, F. A. Flaherty, J. A. Li, S. A. Safron, J. G. Skofronick, T. W. Trelenberg and D. H. Van Winkle, 2001 Annual Joint Symposium of the Florida Society for Microscopy, the Florida Chapter of the American Vacuum Society and Surface Analysis 2001, March 12-15, University of Central Florida, Orlando. 


\section{Progress Report: November 1, 2001 - October 31, 2002}

\section{Aims}

The aim of this work is primarily to study the surface structure and dynamics of insulating surfaces and ultra thin films, using our Helium Atom Scattering (HAS) instrument. We have followed this path because of the unique properties of the HAS instrument which uses a low-energy, neutral He atom beam that does not charge, damage or penetrate the insulating surface. The following is a list of work on-going or planned for this laboratory at this time:

a) We have concentrated most of our recent efforts on metal oxides, particularly $\mathrm{KTaO}_{3}$ (abbreviated KTO) and $\mathrm{KTa}_{1-\mathrm{x}} \mathrm{Nb}_{\mathrm{x}} \mathrm{O}_{3}(\mathrm{KTN})$, where $\mathrm{x}$ is the mole fraction of $\mathrm{Nb}$. These experiments have provided us with an extensive data base on an assortment of unusual surface phenomena, much of what is still being analyzed. b) We have also studied the structure and dynamics of the rutile $\mathrm{TiO}_{2}(110)$ surface. Because of the photocatalytic nature of this surface and our observations of the unusually large temperature dependence of its structure and lattice dynamics, we plan further studies of this surface including the effects induced by various adsorbates. We are also considering experiments to compare these surfaces from single crystal rutile with films of $\mathrm{TiO}_{2}$, which have been prepared by colleagues using laser ablation techniques. c) We want to extend these studies on the metal oxides by examining a target of $\mathrm{SrRuO}_{3} / \mathrm{SrTiO}_{3}(001)$ which we have recently obtained. The $450 \AA$ thick $\mathrm{SrRuO}_{3}$ (SRO) film has the perovskite structure but unlike KTO and KTN is an electrical conductor. While HAS has been employed to study a wide variety of insulators, metals and semiconductors, until now there have been no examples available for comparing the features measured by helium scattering from materials of similar crystalline structures, but very different electronic properties. We expect these studies to prove to be groundbreaking. d) We have so far investigated the microstructure evolution of utrathin films of the aromatic $p$-phenylene oligomer molecules ( $p$-nP, with $n=3$ to 6) adsorbed onto alkali halide substrates by grazing incidence $x$-ray diffraction (GIXRD) and atomic force microscopy (AFM), and to some extent by HAS. Further helium scattering measurements need to be carried out to confirm the evidence relating the structural characteristics of the film that is formed to the growth parameters, the molecular length, the substrate lattice dimensions and, possibly, the surface vibrational modes. The success with the p-nP encouraged us to continue these growth studies to crystals of larger organic molecules, including biocrystals. A colleague in the Biology Department who has offered to collaborate with us in this work can provide crystals of the protein $\alpha$-actinin and help us produce the enzyme lysozyme. However, crystals of the former are typically grown only to micrometer size while 
the latter are close to millimeter size. Thus the lysozyme crystals are similar in cross sectional area to those already studied by HAS. However, we will need to determine the limitations on the size of the molecular crystals that can be studied with HAS and then to adapt the instrument for these investigations. e) One of us (JGS) has been involved with collaborative work at the Max Planck Institute für Strömungsforschung (MPI) in Göttingen, Germany, on $\mathrm{N}_{2}$ and $\mathrm{H}_{2}$ adsorbates on $\mathrm{MgO}(001)$ at temperatures down to $8 \mathrm{~K}$. The experimental work has been completed and two manuscripts are nearing final revisions. The work includes the first helium atom scattering studies of quantum films of $\mathrm{H}_{2}$ and its isotopes on $\mathrm{MgO}(001)$. The new cryostat under construction at Florida State University is nearing completion. We expect to be able to reach 3 $\mathrm{K}$ and plan to extend the German studies to determine the structure and dynamics of better developed films of $\mathrm{H}_{2}$ and its isotopes on $\mathrm{MgO}$ and graphite surfaces. f) We are still proposing to investigate the surface of $\mathrm{NH}_{4} \mathrm{Cl}$ produced from single crystal $\mathrm{NH}_{4} \mathrm{Cl}$ or by reaction of $\mathrm{NH}_{3}$ and $\mathrm{HCl}$ adsorbed onto a suitable substrate. This would be a unique comparison of film structures of identical compounds produced in different ways. g) Another ultrathin film of considerable interest for study is the growth characteristics of $\mathrm{KCl}$ on $\mathrm{NaCl}(001)$. Preliminary work in this laboratory has shown that the initial first few layers grow in a different fashion than subsequent layers. HAS measurements of the lattice dynamics would be very helpful in unraveling the growth processes that are occurring.

The aims of the grant, to study the surface structure and dynamics of insulating materials and ultra thin films, have not changed in any significant way.

\section{Work Accomplished to Date}

The Ph. D. dissertation of Tom Trelenberg reported the experimental work on the surface of $\mathrm{KTN}$ with mole fractions of $\mathrm{Nb}, \mathrm{x}=6,10,20,30$ and 52\%. A previous dissertation by Jaime Li was concerned with similar experiments on KTO. Both of these perovskite materials have provided us with interesting and unusual phenomena. A summary of the main results from these two dissertations are the following: a) The metastable superstructures that form immediately upon cleaving the single crystal samples of KTO or KTN appear to have larger initial dimensions and decay more rapidly with time as $\mathrm{x}$ goes from zero to $52 \%$. b) The distribution of step heights of the stable surface appears to broaden considerably as x increases. c) The structural phase changes in the bulk as the crystal goes from the paraelectric phase to the ferroelectric phases of tetragonal, orthorhombic and rhombohedral structure can been seen at the surface as small changes in helium reflectivity; however, a very large and as yet unexplained, change in the surface reflectivity occurs near $175 \mathrm{~K}$ which appears unrelated to these phase 
transitions. d) The formation of small antiferroelectric domains on the surface which occur very noticeably for KTO appear to diminish with increased $\mathrm{Nb}$ doping, possibly as a result of the competition between the antiferroelectric domains formed in KTO and the increasing ferroelectric nature of the $\mathrm{Nb}$ doped material as $\mathrm{x}$ increases. e) The surface lattice vibrational modes observed include an Einstein-like mode at $\sim 13 \mathrm{meV}$ along with an overtone at $\sim 27 \mathrm{meV}$; the former hardens slightly to $\sim 14 \mathrm{meV}$ as the surface temperature increases from $80 \mathrm{~K}$ to $250 \mathrm{~K}$. In addition, a low energy vibrational mode is found, which appears Einstein-like below $190 \mathrm{~K}$, but which becomes dispersive at higher temperatures. A draft paper on this work should be ready for submission soon. A theorist from the University of Regensburg, Germany, has helped in explaining some of the unusual behavior observed in this research.

More recently, experimental work on the rutile $\mathrm{TiO}_{2}(110)$ surface has been carried out and reported in the $\mathrm{Ph}$. D. dissertation of Elshan Akhadov. The surface structure is very dependent upon heat treatment of the sample. When the surface temperature is kept below about $800^{\circ} \mathrm{C}$, the structure of the surface appears as one would expect for the bulk-terminated (110) surface. However, for the higher temperature studies, crystallographic shear planes develop at the surface, caused by oxygen atoms vacating sites near the crystal surface. To compensate for the oxygen loss, the lattice collapses at a boundary. One manifestation of this seems to be a shift in parallel momentum position, $\Delta \mathrm{K}$ (or scattering angle) of several Bragg diffraction peaks. This is an interesting effect which requires further work. The surface lattice dynamics have been measured in the three high symmetry directions of the rectangular surface Brillouin zone and the preliminary interpretation of the results presented in Akhadov s dissertation has been guided by a comparison to the theoretical model for the rutile $\mathrm{MgF}_{2}(110)$ surface. The $\mathrm{TiO}_{2}$ research has gone well and should be extended to high temperature effects and changes induced by adsorbates.

We have made considerable progress in our studies of ultrathin films of physisorbed $\mathrm{p}-\mathrm{nP}$ oligomers with $\mathrm{n}=3$ to 6 , adsorbed onto $\mathrm{KBr}(001), \mathrm{KCl}(001), \mathrm{NaCl}(001)$, and $\mathrm{NaF}(001)$ substrates. Preliminary measurements of the structure of $\mathrm{p}-4 \mathrm{P}$ on $\mathrm{NaCl}(001)$ were carried out with helium scattering. This work was followed by more extensive investigations with grazing incidence x-ray diffraction (GIXRD) and atomic force microscopy (AFM). The film morphology is very dependent on the length of the molecule (i.e., n), the substrate temperature during deposition and the substrate lattice constant. An example from the GIXRD results reveals a standing orientation for $\mathrm{p}-4 \mathrm{P}$ grown at $50 \mathrm{~K}$ onto a $\mathrm{NaF}$ or $\mathrm{NaCl}$ substrate, but a lying orientation grown onto a $\mathrm{KCl}$ or $\mathrm{KBr}$ substrate. $\mathrm{NaF}(4.64 \AA)$ and $\mathrm{NaCl}(5.65 \AA)$ have smaller lattice constants than the cell parameters of $\mathrm{p}-4 \mathrm{P}(\mathrm{a}=8.05 \AA, \mathrm{b}=5.55 \AA, \mathrm{c}=13.61 \AA)$, whereas 
the larger $\mathrm{KCl}(6.29 \AA)$ and $\mathrm{KBr}(6.59 \AA)$ seem to be able to accommodate the recumbent p-4P. A second example for p-6P ( $\mathrm{a}=8.09 \AA, \mathrm{b}=5.57 \AA, \mathrm{c}=26.24 \AA)$ grown onto $\mathrm{KCl}(001)$ surfaces as a function of substrate temperature shows films with molecules in a lying orientation for substrate temperatures from $25^{\circ} \mathrm{C}$ to $75^{\circ} \mathrm{C}$ and standing orientations for substrate temperatures from $100^{\circ} \mathrm{C}$ to $200^{\circ} \mathrm{C}$, followed by desorption above $225^{\circ} \mathrm{C}$. Yet another case shows a standing molecular orientation for $\mathrm{p}-6 \mathrm{P}$ and $\mathrm{p}-5 \mathrm{P}$ films grown onto $\mathrm{NaCl}$ at temperatures between $125^{\circ} \mathrm{C}$ and $150^{\circ} \mathrm{C}$, but a recumbent orientation for $\mathrm{p}-4 \mathrm{P}$ grown on the same substrate at these temperatures. The massive amount of data collected for these films grown under a wide variety of conditions is still being sorted out. However, it is clear that we are learning to control the molecular orientation for these films. AFM images contribute independent confirming evidence of the modified surface morphologies. The next effort is to return to HAS experiments to explore the surface features of these films more extensively. Two papers on this work have been completed; one has already been published, the other has been accepted for publication. (See Section V.) The major results, briefly discussed above, will be included in additional articles. Clearly, having control over deposited films is a major step toward eventually making planned technological use of the films. (They are interesting as they can be stimulated by uv light to emit polarized blue light. In addition, they might be useful as optical interconnects.) This work has been carried out in collaboration with Dr. D.-M. Smiligies, Cornell High Energy Synchrotron Source, Professor H.-G. Rubahn, Fysisk Institut, Odense Universitet, Denmark, and Drs. S. Rols and K. W. Herwig, Oak Ridge National Lab.

In collaboration with a German group at the MPI in Göttingen, Germany, one of us (JGS) has participated in studies of physisorbed films of molecular hydrogen and its isotopes and $\mathrm{N}_{2}$ on $\mathrm{MgO}(001)$ surfaces at temperatures as low as $8 \mathrm{~K}$. This work has resulted in one paper on the structure and dynamics of a pure $\mathrm{MgO}(001)$ surface and two papers on structure and dynamics of $\mathrm{H}_{2}$ and of $\mathrm{N}_{2}$, respectively, on $\mathrm{MgO}(001)$, which are still being revised by one of the authors. For a single monolayer of $\mathrm{H}_{2}$, three surface phonon modes were observed: two Einstein-like modes near $10 \mathrm{meV}$ and a dispersive mode below $7 \mathrm{meV}$. The experiments with two monolayers of $\mathrm{H}_{2}$ yielded only a single Einstein-like mode at $5 \mathrm{meV}$, but these experiments were limited by the lowest temperature attainable with the German cryostat. Similar experiments for the $\mathrm{N}_{2}$ adsorbate also revealed three Einstein-like modes in the $<100>$ direction. For submonolayer coverage of the film, the modes lay at 2.9, 5.6 and $8.2 \mathrm{meV}$, but with increasing coverage to a full monolayer the $8.2 \mathrm{meV}$ mode decreased to $6.7 \mathrm{meV}$, and new structure for the film was also observed. Unfortunately, with this work the long time collaboration with the MPI has come to an end because the director of their helium scattering laboratory has now retired. 
Extensions of this work are described in the next paragraph.

Other work carried out in the FSU HAS laboratory includes the testing of a new cryostat/manipulator for the instrument, which is being constructed here. This modification to the current instrument will permit measurements to approximately $3 \mathrm{~K}$ and, eventually, to about $0.5 \mathrm{~K}$ when a ${ }^{3} \mathrm{He}$ refrigerator is added. It will make possible detailed studies of quantum films; e.g., of $\mathrm{H}_{2}$ and its isotopes on graphite, $\mathrm{MgO}$ and other substrates. It should also be useful for studies of soft materials, where low-temperature measurements are required for He atom diffraction and inelastic scattering experiments due to the low Debye temperatures of these materials.

\section{Estimate of Unexpended Funds}

We expect to have spent or obligated all of the funds from this grant by the end of the current budget period, October 31, 2002.

\section{Scientific Staff}

The current scientific personnel consist of the principal investigator, JGS (Physics Department) and two co-principal investigators, SAS (Chemistry and Biochemistry Department) and DHVW (Physics Department). We have dropped from three to two graduate students, Mr. E. J. Kintzel, Jr and Ms. R. Fatema. Two students have finished their Ph. D. studies during the last period, Tom Trelenberg, now a postdoc at Lawrence Livermore National Laboratory and Elshan Akhadov, who currently is searching for a postdoc position. The new student, Ms. Fatema, has recently joined our group and will work on the extension of the $\mathrm{TiO}_{2}$ research and then become involved with HAS experiments on soft materials. Also joining us for the past 18 months is Dr. Frank Flaherty of the Physics Department, Valdosta State University, Valdosta, Georgia. He is able to visit FSU one day per week during the academic year and has been collaborating on the interpretation of the organic film work and on the $\mathrm{KTaO}_{3}$ and $\mathrm{KTN}$ experiments. This Spring semester we have had an Honors General Chemistry student, Marissa Ezell, work in our laboratory. A physics undergraduate, James Brock, worked with us on data reduction and many other tasks, including the construction of our cryostat. He left last Spring and has been replaced by Andy Rodriguez another physics undergraduate student.

\section{Publications: Published, Accepted and Submitted, November 1, 2001-October 31, 2002}

1. "Helium Atom Scattering Study of the Surface Structure and Dynamics of in situ Cleaved MgO(001) Single Crystals”, G. Benedek, G. Brusdeylins, V. Senz, J. G. Skofronick, J. P. Toennies, F. Traeger and R. Vollmer, Phys. Rev. B 64, 125421 (2001). 
2. "Observation of a Metastable Periodic Structure for the (100) Surface of $\mathrm{KTaO}_{3}$ after Cleaving in Situ", Jaime A. Li, E. A. Akhadov, Jeff Baker, L. A. Boatner, D. Bonart, F. A. Flaherty, J. Fritsch, S. A. Safron, U. Schröder, J. G. Skofronick, T. W. Trelenberg and D. H. Van Winkle, Phys. Rev. Lett. 86, 4867 (2001).

3. "Investigation of the Morphology of the Initial Growth of Aromatic Molecule pQuaterphenyl on $\mathrm{NaCl}$ (001)”, E. J. Kintzel, Jr., D. M. Smilgies, J. G. Skofronick, S. A. Safron, D. H. Van Winkle, T. W. Trelenberg, E. A. Akhadov and F. Flaherty, J. Vac. Sci. Technol. A 19, 1270 (2001).

4. "Investigation of the Temperature-Dependent Surface Morphology of p-Sexiphenyl Thin Films on KCl(001)”, E. J. Kintzel, Jr., E. S. Gillman, J. G. Skofronick, S. A. Safron, and D.-M. Smilgies (Accepted for publication, Materials Research Society Proceedings, Jan., 2002.)

\section{Abstracts and Papers Presented at Meetings: November 1, 2001-October 31, 2002}

1. "A Study of the $\mathrm{KTa}_{1-\mathrm{x}} \mathrm{Nb}_{\mathrm{x}} \mathrm{O}_{3}(001)$ Surface Using Helium Atom Scattering”, T. W. Trelenberg, J. A. Li, E. A. Akhadov, S. A. Safron, J. G. Skofronick, D. H. Van Winkle, F. A. Flaherty and L. A. Boatner, Workshop on Thin Films, Surfaces and Materials Processing, Newport News, VA, June 6-8, 2001.

2. "Influence of Temperature on the Growth of Crystalline p-Phenylene Oligomer Thin Films", E. J. Kintzel, Jr., D.-M. Smilgies, S. A. Safron, J. G. Skofronick, D. H. Van Winkle and F. A. Flaherty, Workshop on Thin Films, Surfaces and Materials Processing, Newport News, VA, June 6-8, 2001.

3. "A Comparison of the Observed Metastable Periodic Structure for the (001) Surface of $\mathrm{KTaO}_{3}$ after Cleaving under UHV Conditions with Model Calculations for Scattering from a Random Terrace Distribution”, J. D. Brock, E. A. Akhadov, L. A. Boatner, F. A. Flaherty, J. A. Li, S. A. Safron, J. G. Skofronick, T. W. Trelenberg and D. H. Van Winkle, Workshop on Thin Films, Surfaces and Materials Processing, Newport News, VA, June 6-8, 2001.

4. "Preliminary Studies of Surface Structure and Dynamics of Rutile $\operatorname{TiO}_{2}(110)$ Using Helium Atom Scattering”, E. A. Akhadov, J. D. Brock, T. W. Trelenberg, S. A. Safron, J. G. Skofronick, D. H. Van Winkle and F. A. Flaherty, Workshop on Thin Films, Surfaces and Materials Processing, Newport News, VA, June 6-8, 2001.

5. "Structural and Dynamic Behavior of $\mathrm{KTa}_{1-\mathrm{x}} \mathrm{Nb}_{\mathrm{x}} \mathrm{O}_{3}(001)$ Surfaces Investigated by He Atom Scattering”, S. A. Safron, E. A. Akhadov, L. A. Boatner, F. A. Flaherty, J. A. Li, T. W. Trelenberg, J. G. Skofronick and D. H. Van Winkle, Fundamental Physics of Ferroelectrics 
2002, Washington, D. C., February, 2002.

6. "A Study of the Surface Properties of the Mixed Crystal $\mathrm{KTa}_{1-\mathrm{x}} \mathrm{Nb}_{\mathrm{x}} \mathrm{O}_{3}(\mathrm{KTN})$ Using Helium Atom Scattering”, J. G. Skofronick, T.W. Trelenberg, E.A. Akhadov, S. A. Safron, D. H. Van Winkle, L. A. Boatner and F. A. Flaherty, March Meeting of the American Physical Society, Indianapolis, Bull. Am. Phys. Soc. 47, 732 (2002).

7. "Preliminary Results of a Study of the Rutile $\mathrm{TiO}_{2}$ (110) Surface by Helium Atom Scattering”, E.A. Akhadov, J. G. Skofronick, S. A. Safron, D. H. Van Winkle and F. A. Flaherty, March Meeting of the American Physical Society, Indianapolis, Bull. Am Phys. Soc. 47, 1026 (2002).

8. "Investigation of Surface Structure and Dynamics of in situ Cleaved $\mathrm{MgO}(001)$ by Helium Atom Scattering”, J. G. Skofronick, J. P. Toennies, F. Traeger and H. Weiss, Tenth Workshop on Surface Dynamics: Phonons, Adsorbate Vibrations and Diffusion, El Escorial, Spain, June 13-17, 2001.

9. "Microstructure of Organic Thin Films of Electroluminescent Molecules Studied by Grazing-Incidence X-Ray Diffraction”, D.-M. Smilgies, E. J. Kintzel, Jr., J. G. Skofronick and H. Yanagi, Spring 2001, Meeting of the Materials Research Society, San Francisco, CA.

10. "Temperature-Dependent Morphology of Crystalline p-Sexiphenyl Thin Films on $\mathrm{KCl}$ (001)”, E.J. Kintzel, Jr., D.-M. Smilgies, J. G. Skofronick and S. A. Safron, 48th International Symposium of the American Vacuum Society, San Francisco, CA, Fall 2001.

11. "Investigation of the Temperature-Dependent Surface Morphology of p-Sexiphenyl Thin Films on KCl (001)”, E. J. Kintzel, Jr., J. G. Skofronick, S. A. Safron, E. S. Gillman and D.-M. Smilgies, Fall, 2001, Meeting of the Materials Research Society, Boston, MA. 


\section{Progress Report: November 1, 2002 - October 31, 2003}

\section{Aims}

The work carried out during the November 2002 to October 31,2003 period of this grant has remained within the range of the topics expressed in the title of the Grant. Most of the experimental work makes use of our helium atom scattering (HAS) instrument; an instrument constructed here and one that has continued to undergo improvements in both in sensitivity and in automation. The HAS instrument has allowed us to obtain high-quality provocative results in our studies of insulating crystalline surfaces and films.

a) We have concentrated much of our recent efforts on metal oxides; primarily we studied the structure and dynamics of the rutile $\mathrm{TiO}_{2}(110)$ tetragonal surface. This formed the Ph.D. dissertation of E. A. Akhadov, the title is given in Section VII. We measured the surface dynamics of the transverse acoustic mode over a temperature range of $100 \mathrm{~K}$ to $1000 \mathrm{~K}$ in the three high-symmetry directions. There was significant temperature dependence particularly at the surface Brillouin zone center where unusual mode softening and hardening was observed. The dynamical behavior has been submitted as a paper, however, the temperature dependence of the structure remains to be interpreted. We tried one study to compare our single crystal rutile surface results with a film of $\mathrm{TiO}_{2}$, prepared by colleagues using laser ablation techniques. This needs to be further explored.

b) We have analyzed our previous results on $\mathrm{KTaO}_{3}$ and this is the second paper on this seminal work. The previously published paper was a PRL on the metastable behavior of a freshly cleaved $\mathrm{KTaO}_{3}$ surface. The one currently being refereed shows interesting polar nanoregion structure, significant surface temperature dependence, and three surface branches in the two high symmetry directions. We had theoretical support for this paper from a German colleague.

c) We have begun to analyze the surface results from our studies on $\mathrm{KTa}_{1-\mathrm{x}} \mathrm{Nb}_{\mathrm{x}} \mathrm{O}_{3}(\mathrm{KTN})$, where $\mathrm{x}$ is the mole fraction of $\mathrm{Nb}$. These experiments have provided us with an extensive data base on an assortment of unusual surface phenomena mostly on structure and polar nanoregion behavior as a function of $\mathrm{Nb}$ doping.

d) At an earlier time in this grant, we made a preliminary investigation of the microstructure evolution of utrathin films of the aromatic p-phenylene oligomer molecules $(\mathrm{p}-\mathrm{nP}$, with $\mathrm{n}=4)$ adsorbed onto alkali halide substrates by grazing incidence x-ray diffraction (GIXRD), by atomic force microscopy (AFM), and by HAS. This work has now been followed by an extensive investigation by x-ray diffraction and AFM methods. A dissertation by E. Kintzel Jr. 
(listed in SectionVII), resulted from this work. Further helium scattering measurements need to be carried out to confirm the evidence relating the structural characteristics of the film that is formed to the growth parameters, the molecular length, the substrate lattice dimensions and, possibly, the surface vibrational modes.

e) The success with the p-nP encouraged us to do growth studies of crystals of larger organic molecules, including biocrystals. We have a new student undertaking such measurements with the first biocrystal study with HAS. Her efforts have been directed toward the simple amino crystal of 1-alanine.

f) In an earlier report we had mentioned the construction of a cryostat to be used for HAS studies at temperatures near 3-5k. After starting we held back on the completion of the cryostat target holder because one of us (JGS) became involved with collaborative work at the Max Planck Institute für Strömungsforschung (MPI) in Göttingen, Germany, on $\mathrm{N}_{2}$ and $\mathrm{H}_{2}$ adsorbates on $\mathrm{MgO}(001)$ at temperatures down to $8 \mathrm{~K}$. Two manuscripts on clean $\mathrm{MgO}$ and $\mathrm{H}_{2} / \mathrm{MgO}$ have been published and two manuscripts remain, one on beam induced desorption and the second on $\mathrm{N}_{2} / \mathrm{MgO}$. Members of the MPI also studied $\mathrm{H}_{2} / \mathrm{LiF}$ and $\mathrm{H}_{2} / \mathrm{NaCl}$, taken together with $\mathrm{MgO}$, they represent a major improvement in quality and range of molecular hydrogen adsorbate studies.

g) The new cryostat under construction by us needs to be characterized and tested. We expect to eventually be able to reach $3 \mathrm{~K}$ or lower and plan to extend the German studies to determine the structure and dynamics of better developed films of $\mathrm{H}_{2}$ and its isotopes on other alkali halides where we can take advantage of the different lattice spacings and surface corrugations to explore adsorbate-adsorbate, adsorbate-surface interactions and zero point energy behavior. Further, graphite surfaces will also be studied. In the renewal, we describe the many new opportunities available with the completion of the cryostat.

The aims of the grant, to study the surface structure and dynamics of insulating materials and ultra thin films, have not changed in any significant way.

\section{Work Accomplished to Date}

Our measurements were on the structure and lattice dynamics of the rutile $\mathrm{TiO}_{2}(110)$ surface over the temperature range of $100-1000 \mathrm{~K}$. The (110) surface is tetragonal giving three high-symmetry directions. The diffraction measurements in these three directions indicates that almost the entire surface retains the bulk termination (1x1) structure under the preparation conditions employed. However, studies of the step heights between terraces suggest that changes 
occur in these steps for surface temperatures below $200-250 \mathrm{~K}$ even though the diffraction patterns do not reveal any discernable modification of the surface lattice constants over the entire $100-1000 \mathrm{~K}$ temperature range. The diffraction part of this research needs further consideration before it can be published.

The surface phonon dispersion curves in the high symmetry regions of the surface Brillouin zone, obtained through inelastic atom scattering, over the above temperature range reveal changes in the surface forces as the temperature of the surface varies. Of particular interest in these findings is the softening and hardening of the transverse surface acoustic mode at the surface Brillouin zone center as a function of increasing temperature, results very different than those observed from bulk studies. Although model calculations for the dynamics of this surface are not currently available, the observed modes are interpreted, in part, by comparison with calculations reported for the rutile $\mathrm{MgF}_{2}(110)$ surface. A copy of the paper, submitted for the dynamics part of this research, is included with this report; this also formed the Ph.D. dissertation of E. A. Akhadov in the Spring of 2002.

The Ph. D. dissertation of Tom Trelenberg (Fall 2001) reported the experimental work on the surface of $\mathrm{KTa}_{1-\mathrm{x}} \mathrm{Nb}_{\mathrm{x}} \mathrm{O}_{3}$ (KTN) with $\mathrm{Nb}$ mole fractions of $\mathrm{x}=6,10,20,30$ and $52 \%$. This followed a previous dissertation by Jaime $\mathrm{Li}$ who studied $\mathrm{KTaO}_{3}(\mathrm{KT}), \mathrm{x}=0$. Both of these perovskite materials have provided us with interesting and unusual phenomena. During the Grant period of this report, the paper on KT has been written and submitted; a copy is included. A summary of the main results from the KTN dissertation and the KT paper are the following: a) The metastable superstructures that form immediately upon cleaving the single crystal samples of KT or KTN appear to have larger initial dimensions and decay more rapidly with time as $\mathrm{x}$ goes from zero to $52 \%$. b) The distribution of terrace widths of the stable surface appears to broaden considerably as $\mathrm{x}$ increases. c) The structural phase changes in the bulk as the crystal goes from the paraelectric phase to the ferroelectric phases of tetragonal, orthorhombic and rhombohedral structure can be seen at the surface as modest changes in helium reflectivity, but not at the same temperature as observed in the bulk. However, a very large and as yet unexplained, change in the surface reflectivity occurs near $175 \mathrm{~K}$ for KTN that appears unrelated to the phase transitions. d) The formation of small antiferroelectric domains on the surface which occur very noticeably for KT appear to diminish with increased $\mathrm{Nb}$ doping, possibly as a result of the competition between the antiferroelectric domains formed in KT and the increasing ferroelectric nature of the $\mathrm{Nb}$ doped material as $\mathrm{x}$ increases. e) The surface lattice vibrational modes observed include an Einstein-like mode at $\sim 13 \mathrm{meV}$ along with an overtone at $\sim 27 \mathrm{meV}$; the former hardens slightly to $\sim 14 \mathrm{meV}$ as the surface temperature increases from 80 
$\mathrm{K}$ to $250 \mathrm{~K}$. In addition, a low energy vibrational mode is found, which appears Einstein-like below $190 \mathrm{~K}$, but which becomes dispersive at higher temperatures. A theorist colleague, from the University of Regensburg, Germany, has helped in explaining some of the unusual behavior observed in this research.

We should point out that the formation of domains (d) is of considerable interest in general studies of these materials; they are called polar nanoregions (PNR). They form around defects and when the nanoregions are sufficient in size, the structural phase change occurs. Our research has provided the only surface results. We are still trying to interpret the work, but feel the high quality of the surface work provides considerable new insights into the PNR effect. This is work in progress.

We have finished our studies of ultrathin films of physisorbed $p-n P$ oligomers with $n=3$ to 6, adsorbed onto $\mathrm{KBr}(001), \mathrm{KCl}(001), \mathrm{NaCl}(001)$, and $\mathrm{NaF}(001)$ substrates. This formed the dissertation of E. Kintzel, Jr. (Fall, 2002). Previously, preliminary measurements of the structure of $\mathrm{p}-4 \mathrm{P}$ on $\mathrm{NaCl}(001)$ were carried out with helium scattering, with grazing incidence $\mathrm{x}$-ray diffraction (GIXRD) and atomic force microscopy (AFM). The interesting evidence led us to the more extensive study of this year (and the dissertation) using synchrotron radiation and AFM methods. This was a controlled growth study of physisorbed $\mathrm{p}-\mathrm{nP}$ oligomers with $\mathrm{n}=3$ to 6, adsorbed onto $\mathrm{KBr}(001), \mathrm{KCl}(001), \mathrm{NaCl}(001)$, and $\mathrm{NaF}(001)$ substrates. We found the molecular orientation to be very dependent on the length of the molecule (i.e., $\mathrm{n}$ ), the substrate temperature during deposition and the substrate lattice constant. (The films were grown in vacuum onto substrates from $25^{\circ} \mathrm{C}$ to $225^{\circ} \mathrm{C}$ in $25 \mathrm{C}$ steps.) The trends were: 1) some molecules were unable to grow at elevated temperatures, 2) by a suitable choice of molecule, substrate and substrate temperature, the molecules could be made to take a lying or standing orientation, 3 ) when there is a mixture of lying and standing orientations, the fraction of the lying orientations is less than the standing orientation; for example, for $\mathrm{p}-6 \mathrm{P}$ films on $\mathrm{KCl}(001)$, below $100^{\circ} \mathrm{C}$, only lying orientations were observed while at higher temperatures, standing orientations were seen. While the synchrotron studies moved somewhat away from HAS, in the subsequent analysis, we realized how much the two methods complemented each other, particularly for structure. However, the synchrotron study provides nothing on surface dynamics.

This work shows that by picking the combination of molecule, alkali halide lattice and the substrate deposition temperature, that the orientation of the deposited films can be controlled. Two papers on this work have been completed; both have been published and listed previously. One is included in Section V with the reference information, not previously available. The 
major results, briefly discussed above, will be included in additional published articles. Clearly, having control over the structure of deposited films is a major step toward eventually making planned technological use of the films. (They are interesting as they can be stimulated by uv light to emit polarized blue light. In addition, they might be useful as optical interconnects.) This work has been carried out in collaboration with Dr. D.-M. Smiligies, Cornell High Energy Synchrotron Source, Professor H.-G. Rubahn, Fysisk Institut, Odense Universitet, Denmark, and Drs. S. Rols and K. W. Herwig, Oak Ridge National Lab.

The success of the studies on the soft materials above served as a jumping off place for a further, more involved study on the surface behavior of biocrystals. A new student wanted to do research in the area of biophysics. Having finished the work on soft materials by E. Kintzel Jr., we took his work to the next level. This will see how far we can push HAS into the more complicated arena of surface behavior of biocrystals. We have settled our beginning efforts on crystals of simple amino acids starting with 1-alanine as our first candidate for research. We started by growning the crystals from an aqueous solution where we found the samples to be very hygroscopic. When we used the crystals as samples in the HAS instrument, we found it difficult to remove the water. We then tried growing the samples on a substrate by vacuum deposition with the 1-alanine source in the HAS scattering chamber. Since the 1-alanine vapor pressure is significant, we ended up coating the inside of the scattering chamber with the 1alanine. This was unsuitable so we are currently modifying the scattering chamber to add a separate vacuum system to hold the 1-alanine so we can bake the main chamber for better vacuum conditions and use collimators to restrict the amount of 1-alanine going into the scattering chamber during the growth of the layer. We regard this as work in progress.

In collaboration with a German group at the Max Planck Institut für Strömungsforschung (MPI) in Göttingen, Germany, one of us (JGS) participated in studies of physisorbed films of molecular hydrogen and its isotopes and $\mathrm{N}_{2}$ on $\mathrm{MgO}(001)$ surfaces at temperatures as low as 8 $\mathrm{K}$. This work has resulted in two published papers, one on the structure and dynamics of a pure $\mathrm{MgO}(001)$ surface and second on the structure and dynamics of $\mathrm{H}_{2}$ on $\mathrm{MgO}(001)$, the latter listed in Section V. A third paper with the adsorbate $\mathrm{N}_{2}$, is still being revised by one of the authors.

The results of these measurements were described in the last progress report and will not be included again. Instead, we comment that the German collaboration has taught us that films of simple molecules can be grown on $\mathrm{MgO}$ at sufficiently low temperatures and we can study the structure, the growth behavior and the surface dynamics of these films. The HAS instrument 
represents a much better probe for simple atom/molecule adsorbate studies than transport or neutron studies where $\mathrm{He} / \mathrm{H}_{2}$ studies, for example, have been done on $\mathrm{MgO}$ powder or sheets of graphite that acts similar to $\mathrm{MgO}$, like a powder. With HAS, we can study the adsorbate behavior on just about any crystalline surface and find the surface structure and dynamics, the latter not possible with the powder type samples. We need only surface areas of a few $\mathrm{mm}^{2}$. These are ideal systems for fundamental studies of the simplest atoms and molecules on a surface. Further, a theoretical colleague is available for first principle theoretic interpretation for our planned work.

This has reinforced our belief on our original proposed work with the cryostat stage. We had started the construction of a cryostat, but slowed down during this German collaboration to see what would result from their work. In the meantime we continued the measurements on the KTN samples. The German lab has now closed because of the required retirement of the director and all of the instruments have been moved or dismantled. We feel that our instrument, with a cryostat designed to reach below $3 \mathrm{~K}$ with liquid helium cooling, and below $2 \mathrm{~K}$ with the addition of a ${ }^{3} \mathrm{He}$ evaporating stage should now be finished and used on the experiments discussed in the last renewal proposal and further elaborated on in this new renewal proposal.

\section{Estimate of Unexpended Funds}

We expect to have spent or obligated all of the funds from this grant by the end of the current budget period, October 31, 2003.

\section{Scientific Staff}

The current scientific personnel consist of the principal investigator, JGS (Physics Department) and two co-principal investigators, SAS (Chemistry and Biochemistry Department) and DHVW (Physics Department). Two students have finished their Ph. D. studies during the last period, Elshan Akhadov, now a postdoc at Los Alamos National Laboratory and Ed Kintzel Jr. who currently is in a postdoc position at Argonne National Laboratory. A new student, Ms. Fatema, has recently joined our group and has worked on the extension of the $\mathrm{TiO}_{2}$ research to become familiar with the HAS instrument; currently, she is using HAS to explore the surfaces of soft biocrystals. Two other students have joined our group, one already in place part time while the second will join in the summer. Also collaborating with us for the past 30 months is Dr. Frank Flaherty of the Physics Department, Valdosta State University, Valdosta, Georgia. He is an expert in infrared spectroscopy and visits FSU one day per week during the academic year and will continue to assist us in the interpretation of our results. He is also supervising Brian DuBose, a Valdosta State physics major, in a senior project. This project involves measuring the 
temperature dependence of the dielectric constant of one of our $\mathrm{TiO}_{2}$ samples that shows unusual hysteresis features. We also collaborate on soft materials with Professor Horst-Guenter Rubahn. Odense Universitet, Denmark and Dr. Detlef Smilgies, Cornel University Synchrotron Source. This Spring semester we had a Honors General Chemistry student, Melanie McClain, work in our laboratory. She has successfully grown crystals of 1-alanine for our biocrystal research. A physics undergraduate, Andy Rodriguez, worked with us on data reduction and many other tasks. He will leave here at the end of summer to attend graduate school at Louisiana State University where he has won a Sloan Minority Scholarship to support his graduate work.

\section{Publications: Published, Accepted and Submitted, November 1, 2002-October 31, 2003}

1. "Helium Atom Scattering Studies of the Structure and Vibrations of $\mathrm{H}_{2}$ Physisorbed on MgO(001) Single Crystals”, J. G. Skofronick, J. P. Toennies, F. Traeger and H. Weiss, Phys. Rev. B 67, 35413 (2003).

2. "Artifacts in Helium Atom Surface Scattering (HAS) Time-of-Flight Spectra: A New Encounter with Deceptons", E. A. Akhadov, T. W. Trelenberg, S. A. Safron, J. G. Skofronick, D. H. Van Winkle, F. A. Flaherty and W. Theis, Phys. Rev. B 67, 113406 (2003).

3. "Surface Structure and Lattice Dynamics of Rutile $\mathrm{TiO}_{2}(110)$ Using Helium Atom Scattering", E. A. Akhadov, S. A. Safron, J. G. Skofronick, D. H. Van Winkle, F. A. Flaherty and Rifat Fatema, Phys. Rev. B. (in press).

4. "Surface Structure and Dynamics of $\mathrm{KTaO}_{3}(001)$ ", J. A. Li, E. A. Akhadov, Jeff Baker, L. A. Boatner, D. Bonart, J. Fritsch, S. A. Safron, U. Schroeder, J. G. Skofronick and T. W. Trelenberg, Phys. Rev. B (in press).

5. "Investigation of the Temperature-Dependent Surface Morphology of p-Sexiphenyl Thin Films on $\mathrm{KCl}(001)$ ), E. J. Kintzel, Jr., E. S. Gillman, J. G. Skofronick, S. A. Safron, and D.-M. Smilgies, Mat. Res. Soc. Symp. Proc., Vol 708, BB10.1.1 (2002). Previously reported, but without reference information.

6. "Analysis of Nanostructured Blue-Light p-6P Films on Mica”, F. Balzer, E. J. Kintzel, Jr., J. G. Skofronick, S. A. Safron and H.-G. Rubahn, SPIE, 4800 (2002).

\section{Abstracts and Papers Presented at Meetings: November 1, 2002-October 31, 2003}

1. "Helium Atom Beam Induced Desorption of $\mathrm{H}_{2}$ From a Weakly Bound $\mathrm{H}_{2} / \mathrm{MgO}$ System”, J. G. Skofronick, J. P. Toennies and F. Traeger, Bull. Am. Phys. Soc. 48, 325 (2003).

2. "Surface Structure and Lattice Dynamics of Rutile $\mathrm{TiO}_{2}(110)$ Using Helium Atom 
Surface Scattering”, Rifat Fatema, E. A. Akhadov, S. A. Safron, J. G. Skofronick, D. H. Van Winkle and F. A. Flaherty, Bull. Am. Phys. Soc. 48, 1095 (2003).

3. "Microstructure Evolution of Ultrathin p-Phenylene Oligomer Films", E. J. Kintzel, Jr., D.-M. Smilgies, J. G. Skofronick, S.A. Safron, and D.H. Van Winkle. Presented at the Thin Films, Surfaces, and Materials Processing Workshop, and the Mid-Atlantic Chapter of the American Vacuum Society.

4. "Results of a Study of the Rutile $\mathrm{TiO}_{2}(110)$ Surface by Helium Atom Scattering”, J. G. Skofronick, E. A. Akhadov, S.A. Safron, and D.H. Van Winkle and F. H. Flaherty. Presented at the Thin Films, Surfaces, and Materials Processing Workshop, and the Mid-Atlantic Chapter of the American Vacuum Society May (2002).

VII. Dissertations: November 1, 2002-October 31, 2003

Surface Lattice Structure and Dynamics of Rutile $\mathrm{TiO}_{2}(110)$, E. A. Akhadov, Ph.D. Dissertation, Florida State University, Spring Semester (2002).

Controlled Growth of Ultrathin Molecular Films of the p-Phenylene Oligomers on Alkali Halide Substrates, E. J. Kintzel Jr., Ph.D. Dissertation, Florida State University, Fall Semester (2002). 